\title{
A PRELIMINARY REPORT ON DETERIORATION IN THE WESTERN HEMLOCK-DOUGLAS FIR TYPE ON LOWER VANCOUVER ISLAND FOLLOWING ATTACK BY THE WESTERN HEMLOCK LOOPER (LAMBDINA F. LUGUBROSA) (Lepidoptera, Geometridae) ${ }^{1}$ \\ by R. E. Foster AND D. R. HURN \\ Dominion Laboratory of Forest Patbology, Victoria, British Columbia
}

At the request of the forest industry and in cooperation with the Division of Entomology, studies were initiated during the summer of 1948 in order to determine the nature and extent of the decay losses and the rate of progressive deterioration in stands of hemlock looper-killed timber on lower Vancouver Island.

The problem of assessing the progressive losses from decay is a matter of great concern in this region. It has been estimated that approximately $400,000,000$ board feet of timber have been killed. Since a large percentage of this killing has taken place in stands that were to be held in reserve for future cutting, a drastic change in the management policy for this region has been necessary. Extensive salvage operations have been planned for most of the areas involved. The major problem which now confronts the logging companies concerned is that of determining the maximum period during which decay and other losses will remain small enough to permit economic utilization. In order to obtain this information representative areas have been set aside for study. To date, sample plots containing 1,500 trees, approximately 50 per cent of which are dead, have been established for this purpose in five separate localities.

A preliminary analysis of the decay losses has been undertaken in one of the areas in question, the Sarita River valley on the west coast of Vancouver Island. To date, four permanent sample plots containing 25 dead trees and a random sample of $\mathbf{1 4 0}$ trees from adjacent areas have been examined in this locality. During the field examination sample trees were inspected at ten-foot intervals throughout their total height. Sections of the wood were removed, examined for decay, and the causal organisms isolated in order to confirm the presence of rot and to verify the identifications. Each tree was then scaled to obtain data in regard to volume and other pertinent information.

In the case of the random sample of 140 trees the following information has been obtained for western hemlock:

$$
\begin{aligned}
& \text { classed as insect-killed ..................................... } 86 \text { per cent } \\
& \text { classed as living …...................................... } 13 \text { per cent } \\
& \text { classed at cull trees prior to the insect attack .... } 1 \text { per cent }
\end{aligned}
$$

Twelve per cent of the insect-killed trees were classed as "understory" since

\footnotetext{
1 Contribution No. 981, Division of Botany and Plant Pathology, Science Service, Department of Agriculture, Ottawa, Canada.
} 
they did not meet the minimum size requirements for utilization. The gross merchantable volume of the remaining dead trees amounted to about 140,000 board feet, or 83 per cent of the stand. This latter volume has been analysed with respect to the accumulated losses through decay, sap stain, and secondary insect attack. The information obtained in the case of the losses attributed to disease may be summarized as follows:

1. Ninety-eight per cent of the trees have become infected with saprot subsequent to the insect attack.

2. The percentage of the total length of the merchantable bole in which decay was recorded increased progressively from 45 per cent in the 15 -inch to 83 per cent in the 40 -inch diameter class. In the tree of average size decay had become established throughout 95 feet, or 81 per cent of the merchantable length.

3. The incidence of infection increased markedly with increase in height:

Distance from

stump height

$1-40 \mathrm{ft}$.

$41-80 \mathrm{ft}$.

$81-120 \mathrm{ft}$.

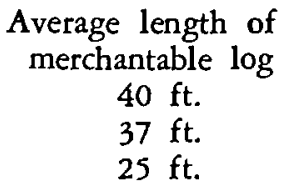

Average length free from decay

$22 \mathrm{ft}$.

$4 \mathrm{ft}$.

$1 \mathrm{ft}$.

4. In the infected portions of the merchantable bole an average radial penetration of advanced and incipient decay of 1.5 inches was recorded. Individual cases of penetration up to 6 inches were measured.

5. The percentage of the merchantable volume occupied by decay decreased slightly with increasing diameter. Twenty-three per cent of the volume was involved at 15 inches and 18 per cent at 50 inches. The average extent of decay in the 106 trees represented 22.4 per cent of the gross merchantable volume.

6. Only partial information has been obtained as to the identity of the decay organisms associated with deterioration. To date, however, six different fungi have been identified following intensive cultural studies. These are Fomes pinicola (Sw.) Cke., Ganoderma oregonense Murr., G. applanatum (Pers.) Pat., Poria tsugina (Murr.) Sacc. \& Trott., Polyporus abietinus Dicks. ex Fr., and Stereum sanguinolentum Alb. \& Sch. A greater proportion of the total decay has been assigned to Fomes pinicola than to any other organism isolated to date. This fungus produces a brown cubical rot and in the advanced stages of decay renders wood useless both for lumber and pulpwood production. Previous studies have indicated that even early or incipient stages of this decay may seriously reduce certain strength properties. Further sampling will be undertaken in order to clarify the present decay complex and rate the various organisms according to their incidence and relative importance.

It has been stated that decay organisms have affected 22.4 per cent of the gross merchantable volume. In recording the decay volumes for this preliminary analysis both advanced and incipient stages of decay have been 
included. It is not to be implied, therefore, that over 22 per cent of the gross volume has been destroyed. The percentage indicated may be referred to as the "theoretical loss". The actual loss that will be realized in practice will vary with the degree and type of salvage utilization attempted. It is probable, for example, that in cases where the salvaged material is to be used as pulpwood only the advanced stages of decay will be considered as cull. Under such circumstances the theoretical loss would be reduced appreciably. In this connection, however, it should be noted that incipient decay and stained material contribute to a reduction in both the quality and yield of pulp.

The preceding discussion has dealt primarily with the decay losses that have accumulated in western hemlock up to the summer of 1948 . No similar detailed information has yet been obtained in the case of Douglas fir and balsam fir, the two other species involved in the present study. On the basis of extensive observation, however, it is believed that the losses in balsam fir will be greater and those in Douglas fir less than in the case of western hemlock.

Insufficient data have been obtained to date to provide reliable information relative to the progressive rate of deterioration and the probable period during which economical salvage will be feasible. A further analysis of permanent sample plots will be undertaken during 1949 in order to provide a basis for predictions of this nature. 